\title{
Legal Protection Study on Research Findings Commercialization Policy Under New Normality
}

\author{
Xiaoling Zhang \\ Xi'an University of Technology, Xi'an Shaanxi, 710054, China
}

Keywords: New normality, Research findings commercialization, Legal protection.

\begin{abstract}
With economic development has entered a "new normal" level of industrial structure and escalating productivity as an important scientific and technological achievements, can effectively improve productivity, effectively improve the efficiency of athletics, and all this must rely on scientific and technological achievements take root, namely transforming scientific and technological achievements. In this high-tech breeding process, the researchers not only need to work, and is also inseparable from security-related laws and regulations. In this paper, based on existing laws and regulations, technological achievements into perspective in the New Situation normal country, conduct comparative research, in-depth study of issues related to the institutional level, put forward a sound advice from the perspective of legal protection.
\end{abstract}

\section{Introduction}

Used to call the "old normal" refers to the investment level of intensity as the primary driving force of economic development, in order to maintain a GDP growth of a relatively extensive economic mode. However, with the continuous development of society, once the initial stage of the inherent social welfare started to decrease, and therefore we are faced with new challenges and opportunities for development. Traditional economic development began to change the core driving force in the pursuit of growth, it began production efficiency further requests, the "new normal" is to ask the change past patterns of development, the pursuit of healthy and stable development of the new economic model.

Standing history of economic development in the new normal node, embodied in the scientific and technological aspects of innovation, an important manifestation, to enhance the conversion efficiency of scientific and technological achievements. In this process, perfect, powerful security system-level laws and regulations, has become a key element can be achieved.

\section{Characteristics of research findings commercialization under new normality}

New normal economic and social development, scientific and technological achievements is also showing a new normal, a lot of the past no longer distinct characteristics embodied, but showing a lot of modern features, manifested in the following aspects:

\section{Research findings commercialization number grows rapidly}

Since the call for States to a universal innovation and entrepreneurship, social investment in innovation and entrepreneurship continues to increase, this innovation, and is a direct result reflects the geometric growth in the number of high-tech achievements, so that scientific and technological achievements into a higher requirements, scientific and technical control of them, but also more demanding protection of property rights, more protection for the core technology requirements, and 
thus also contributed to the development of related industries, to promote birth to a large number of high-tech achievements [1].

\section{Disputes keep increasing}

Under the new normal, corporate foreign exchange continued to increase such exchanges, not only in the domestic competition among enterprises, but also in the international competition, not just in competitive firms, among upstream and downstream enterprises, but also in different industries, among the different levels of the enterprise, with the economic openness on the rise, such disputes will be more and more.

\section{Scientific and technological achievements commercialization runs faster}

Under the new development situation, the escalation of traditional industries, new industries are generally characterized by the integration of high-tech knowledge, relevant national laws and policies, but also continue to promote the growth of clusters of related industries, therefore, for the needs of scientific and technological achievements have changed even more urgent, but also require improving the speed of scientific and technological achievements.

\section{Realistic difficulties of research findings commercialization under new normality}

\section{Imperfect laws and regulations}

Transforming scientific and technological achievements, from the laws and regulations system security policy is concerned, there are two levels, the first after the scientific and technological achievements have been developed, how effectively translated into intellectual property rights, protected by law, become the legal protection of state science and technology, That there is a problem, which deal with science and technology for protection, given what science can not give protection, in addition to its protection how big the problem is the law to be considered; second, scientific and technological achievements to leave the lab and into the market circulation of patent or other scientific and technological achievements in this period, and how to protect and give much protection, but also to focus on the problem of the existing law.

Under the existing laws and regulations on the protection of scientific and technological achievements, including the following three aspects;

First, in the form of intellectual property protection given to scientific and technological achievements, which is in the transformation of scientific and technological achievements, with the largest one level, that is, holders of scientific and technological achievements by the national patent applications, according to China's "Patent Law" stipulates that patent protected into inventions, utility models, industrial designs and other long this protection period, forceful, but there is often difficult to achieve a big problem, and there is the problem of long implementation cycle. In practice, the biggest problem is legal, there are also a matter of time.

Second, the "Anti-Unfair Competition Law," "anti-monopoly law," and so on, even including the "Tort Liability Act" in certain provisions, are the results of the technical secret protection, for the protection of technical secrets, and it is clear that these legal provisions not well play a full role in safeguarding the relevant infringement cases in the country frequently, is the best proof of this phenomenon, the Western developed countries, not only the importance of protection of intellectual property, but also attaches importance to protect technical secrets, because intellectual property rights there is a certain period of protection, there is also the problem of the patent cliff, which for many companies and negative, like Coca-Cola recipe questions for centuries, while giving protection by way of trade secrets, did not apply for a patent, but in our country, so technology, intellectual property rights do not apply once, it is likely to cause leakage of the question, "anti-unfair competition law" and other norms and there are too empty question, practical operation is rather poor, and such a 
problem, return to the "tort liability Act "[2], you have to rely on the simple concept of civil law to address professional business issues, there are some difficulties.

Thirdly, it is by contract to protect the technical and technological achievements, which is the lowest level of the lowest-order bits of a protection method, this legal basis, from the "Contract Law" in the relevant sub-contract provisions on technology as a sector law a chapter, such provisions can easily exhaustive, such a problem in the civil law provisions, due to less provisions applicable in particular, the provisions applicable give a great deal of room for interpretation, must go hand in hand, explaining the difficulty will increased, with a lot of controversial decision, which is not conducive to strengthening understanding of the outside world, the role of the guidelines of the law has not been fully realized. Admittedly, the "Contract Law" [3] is China's existing laws and regulations, the higher the quality of a law, but in the "Contract Law" sub-rule, the relevant provisions on technology contracts, since only part of the contents, there must be space and lack of consideration on the specific details, so to strengthen the relevant legislation still needs now is the reality of scientific and technological achievements.

\section{Judicial practice protection is insufficient}

Under today's society, the lack of intellectual property protection efforts, already restricting scientific and technological achievements of a great resistance, the reason, the problem is not only the provisions of the above mentioned laws and regulations applicable in the legal level, there are also many question, the most prominent is not enough emphasis, protection efforts is not big enough. By retrieving data system, not difficult to find historical precedent court cases of infringement of intellectual property case acceptance and damages the amount of view, there is a problem of insufficient strength, and Western developed countries, compared to generally exist relatively large gap.

For this phenomenon, is now changing, and now, in Beijing, Shanghai, Guangzhou, our country has established a relevant intellectual property court, for special cases are heard, these indicate that China's protection of intellectual property rights, are promoted to a new level, however, from the individual consciousness, the emphasis on intellectual property rights is still not enough compared to Western countries, the popularity of IP-related laws and regulations, there are still many deficiencies, the protection of intellectual property business consciousness, there are also a lot to be desired. Under normal circumstances, the promotion of scientific and technological achievements, but also need to protect the specialized agencies, but our lack of appropriate specialized agencies, and the lack of appropriate regulatory regimes, and also restricting the process of scientific and technological achievements.

\section{Comparison and reference of scientific and technological achievements transformation legal protection}

In the form of law, promoting promote scientific and technological achievements, it is a common practice in many advanced countries. Traditional scientific and technological achievements, needs a lot of money, generally through patented technology trade to achieve, but in the new economic and social environment, greatly increasing the number of scientific and technological achievements, but a lot of scientific and technological achievements of the life cycle, but as before long, under such circumstances, it is necessary to introduce such a fund raising venture capital practices in many advanced Western countries is to establish a sound legal mechanism to encourage venture capital [4].

With the integration of world economy, science and technology circulate faster, which also allows the high-tech industry presents different from the past and new features, this new feature, called for strengthening the exchange of scientific and technological innovation between subjects, expanding cooperation and open up scope of cooperation. From a global perspective, all countries attach great importance to this. [5]. 
In the system development process to take over the United States in the regulations on the basis of the previous, but also according to their national conditions with timely adjustments, such as through the "National Research Act," subject to technological innovation and so are strongly encouraged to encourage their development applications and other aspects of cooperation, and promote transformation of achievements floor. Since then a number of years, the United States has issued a number of bills to encourage enterprises to promote the transformation of scientific and technological achievements, and promote a higher level of mutual cooperation. Which include not only the domestic sectors of cooperation, including high-level scientific cooperation technological innovation internationally. In the ensuing decade, a number of high-tech joint development project between the United States, Japan and the EU generally carried out to achieve a successful transformation of scientific and technological achievements.

\section{Suggestions for technological achievements transformation legal protection}

\section{Overall planning of three-dimensional legal system}

Under the new normal, scientific and technological achievements of the floor, but also indicate the direction of its legal system, the lack of co-ordination thinking and organizational departments, various laws and regulations often cross or confused, or appear blank areas cannot be regulated, based on this, we need to plan legal system, changing those policies of the status quo, to take three-dimensional legal system, improve relief, encouragement, compensation, compensation levels and other legal requirements, to meet the real needs of scientific and technological achievements into law.

In terms of legislation, since the majority of the existing laws and regulations are specified in the "General Principles of Civil Law," "Tort Liability Act" or other branches of law, the specific regulations only "Patent Law", "Anti-Unfair Competition Law", for the scientific and technological achievements special provisions, there are still some missing, and in particular the application process, but also there is a conflict special law and general law in the application and the lack of coordination of the place, and therefore requires laws and local regulations, the NPC formulated industry standards, co-ordination, speed up scientific and technological achievements into special legislation to promote the process, to form an effective three-dimensional framework of legal safeguards.

\section{Complete supporting measures and promote transformation}

The law does not just discipline, a lot of support services and policies and regulations, but also the need to protect the institutional level, for the transformation of scientific achievements and personnel placement, corporate incentives, the goal posts set up, as well as system construction, require proper arrangements system, by improve the relevant laws and supporting measures to further promote support measures in place for the effective transformation of scientific and technological achievements, to lay a solid foundation, and eventually landing scientific and technological achievements.

In supporting the conversion of scientific and technological achievements not only need basic system, but more importantly, local regulators and the industry to encourage the implementation of reward and punishment, in addition to tort liability, but also to strengthen the industry constraints, through the establishment of industry access, industry incentives and other measures to promote scientific and technological achievements into the ground, lack of related rules and norms, is an important cause of poor scientific and technological achievements. In addition, research and development in science and technology, the introduction of talent all over policies and achievements incentives, but in the actual implementation process, due to the instability of the policy, there are certain problems in terms of cash, thus affecting the process of scientific and technological achievements. 


\section{Enhance law enforcement}

Under the new normal, we must continue to crack down on enforcement, patents, trademarks and copyrights and other intellectual content, incorporated into the collaborative management system, so that more powerful functions, assume corresponding responsibilities, increasing the counterfeiting, piracy and other violations of the crackdown, continue to step up publicity efforts, so that law enforcement agencies have a higher social impact, will focus on the case, be released to the community, science and technology to create a social environment protection, no rights to the ability of the Victim, through legal aid system to help safeguard their rights.

Throughout the case of intellectual property rights, in terms of law enforcement and illegal punishment, there is obviously insufficient efforts on science and technology with foreign infringement cases frequently astronomical compared to the compensation due to the stage of socio-economic development, as well as specific national conditions and cultural awareness, in the amount of compensation and penalties for violations, the general trend towards lightweight process, along with economic development has entered a new normal, increased illegal disciplinary efforts, through typical cases establish, strengthen people's awareness of the law, is very necessary and efficient way.

\section{Conclusions}

Based on the above analysis, not difficult to see under normal build new scientific achievements into perspective of the legal system, we need to take into consideration, considering the introduction of legislation and policy design issues from the economic, social and other multi-faceted angles, including not only improve the system at the same time Thought also needs to spread awareness level, long way to go, with the further development of science and technology and the advent of the knowledge economy forward, our country will eventually usher in a perfect, scientific and technological achievements transformation system.

\section{Acknowledgments}

This paper is a project of Shanxi Province Education Department humanities \& social sciences fund (No.: 13Jk0085)

\section{References}

[1] Zhang Wujun, Xu Ning. Legal protection study on research findings commercialization policy support under new normality.Technology progress and measures,2016(3):109-112.

[2] Qin Jie, Song Wei. On the revision of Code of scientific and technological achievements transformation promotion. China Science Forum,2014(4):10-14.

[3] Guo Yuyan. Legal protection system to promote Science and Technology Achievements Transformation-a perspective of law economic analysis. Journal of Shanxi Agricultural University(social sciences edition),2016,15(5):375-380.

[4] Zhou Junqing, Xu Yibo. Legal issues of university of Science and Technology Achievements Transformation under Collaborative Innovation Perspective. Journal of Hefei Polytechnic University(social sciences edition),2013,27(1):39-42.

[5] Guo Li. Intellectual property problem in scientific and technological innovation and achievements transformation. Scientific management,2010,28(2):117-120. 